\title{
Formulation and Physical Stability Testing of Chitosan Gel from Vaname Shrimp Shell (Litopenaeus vannamei) with Carbopol 940 Gelling Agent
}

\author{
Norisca A. Putriana*, Taofik Rusdiana , M. A. A. Prakoso \\ Department of Pharmaceutis and Pharmaceutical Technology, Faculty of Pharmacy, Universitas Padjadjaran \\ Jl. Raya Bandung Sumedang KM 21 Jatinangor Sumedang
}

Received: 17 May 2019/Revised: 23 May 2019/Accepted: 18 Sep 2019/Published: 1 Oct 2019

\begin{abstract}
Wound is defined as a disorder of normal anatomy and skin's function that occurs as a result of tissue injury or pathologic process resulting in epithelium discontinuity, with or without lossing underlying connective tissue. The use of chitosan in medicine, especially in surgery, gives many advantages in terms of wound healing that stimulates hemostasis of cell. Chitosan gel is one of alternative wound treatments that still needs improvement, especially in terms of the effectiveness of the formulation. In this study, physical stability of chitosan gel formulations was tested in various concentration of carbopol 940 as a gelling agent i.e, $0,5 \%, 1 \%$ and $1,5 \%$. The parameters observed during the physical stability testing of this gel research were $\mathrm{pH}$, viscosity, spreadability, homogeneity, organoleptic and sineresis gel. The result of the physical stability testing of chitosan gel stored for 56 days showed that formula 1 has the best result according to all parameters. Formula 1 has $\mathrm{pH} 5,8-6,2$ at $25^{\circ} \mathrm{C}$ and $40^{\circ} \mathrm{C}$, the best organoleptic stability, viscosity shift $9 \%$ at $25^{\circ} \mathrm{C}$ and $13,8 \%$ at $40^{\circ} \mathrm{C}$, spreadability shift $10,9 \%$ at $25^{\circ} \mathrm{C}$ and $14,4 \%$ at $40^{\circ} \mathrm{C}$. In conclusion, the best chitosan gel formulation for physical stability testing is chitosan gel with carbopol 940 concentration of $0.5 \%$
\end{abstract}

Keywords: Wound, Chitosan gel, Physical Stability

\section{Introduction}

The skin is the largest organ as well as the outermost part of the human body. The main function of the skin is as a protective organ against the environment. Injuries occur if the skin tissue is damaged. Injuries can be caused by sharp or blunt objects, temperature changes, chemicals, explosions, electric shock, or animal bites [1]. An incision wound is a wound caused by a sharp instrument, for example, a wound caused by surgery.

Chitosan is a derivative of chitin after deacetylation. Chitosan is composed of $\beta(1,4)$ -2-amino-2-deoxy-D-glucose chemical formula, a natural polymer that can be used as a natural biomaterial to repair damaged tissue because it has several advantages over synthetic biomaterials [2]. The use of chitosan in medicine, especially in surgery, has many advantages for wound healing, In this case, to stimulate hemostasis (increase the proliferation of fibroblast and extracellular matrix $(\mathrm{ECM})$ ), and also to accelerate the generation of tissue [3].
Chitosan has antibacterial and antifungal effect, and anthelmintic activity that will prevent it from microbes. In addition, chitosan also has effects working as wound healing, anti-inflammatory, sunscreen, moisturizer, and immunomodulator agents [4].

The use of chitosan gel is one of alternative wound treatments that still requires improvement especially in terms of effectiveness of the formulation. This is what makes the researcher interested in learning how the formulation of a gel chitosan that uses carbopol as its base is considered good in terms of both its formula and its physical stability.

\section{Materials and Methods}

\subsection{Tools}

The tools used in this research were mortar, stamper, measuring glass (pyrex), beaker glass (pyrex), analytical balance (Scout-pro), mechanical stirrer (IKA Eurostar), pH meters (sevenEasy s20Mettler Toledo), Brookfield DV-E viscometer, spatula, refrigerator, and aluminum foil. 


\subsection{Materials}

The materials used in the research were Propylene glycol, Acetic Acid, Chitosan (Indonesian Ministry of Marine Affairs), Carbopol 940, Methylparaben, Propylparaben, Triethanolamine, and Distilled Water.

Tabel 1. Chitosan Gel Formulation

\begin{tabular}{llll}
\hline \multicolumn{1}{c}{ Materials } & \multicolumn{1}{c}{ F1 } & \multicolumn{1}{c}{ F2 } & \multicolumn{1}{c}{ F3 } \\
\hline Acetic Acid 1 \% & 5 & 5 & 5 \\
Propylene glycol & 10 & 10 & 10 \\
Chitosan & 1 & 1 & 1 \\
Carbopol 940 & 0,5 & 1 & 1,5 \\
Methylparaben & 0,1 & 0,1 & 0,1 \\
Propylparaben & 0,01 & 0,01 & 0,01 \\
Triethanolamine & 0,25 & 0,25 & 0,25 \\
Distilled Water & Ad 100 & Ad 100 & Ad 100 \\
\hline
\end{tabular}

\subsection{Procedure of Making 1\% Chitosan Gel}

Heat up the distilled water which will be used as a carbopol sweller up to $70^{\circ} \mathrm{C}$. Then swell the $0.5 / 1 / 1.5 \%$ carbopol by using distilled water for \pm 30 minutes and stir it continuously by using a mechanical stirrer until the entire carbopol dissolved. Mix the materials one by one until it all becomes homogeneous.

\subsection{Physical Stability Testing}

Physical Stability Test in this research was conducted for 2 months storage period at room temperature $\left(27 \pm 2^{\circ} \mathrm{C}\right)$ and high temperature $(40 \pm$ $2^{\circ} \mathrm{C}$ ). The parameters of stability testing observed were organoleptic, homogeneity, $\mathrm{pH}$, viscosity, diverse power, and cycling test. These parameters were observed at the point of day $0,7,14,21,28$, 42 , and 56. In addition to these parameters, there is also an additional parameter, namely hedonic test.

\subsection{Data Analysis}

Data obtained were processed statistically using SPSS software. The analysis done was the normality test (Shapiro-Wilk) and homogeneity test (Levene test). To see the relationship between treatment groups, one-way variance analysis (ANOVA) is performed if the data are normally distributed and homogeneous. If the data are not normally distributed, then Kruskal-Wallis analysis is performed.

\section{Results and Discussion}

\subsection{The Results of Gel Chitosan Formulation}

The form made in this research was hydrogel. Hydrogel is chosen because it has a good dispersive power on the skin, does not disrupt the physiological function of the skin, provides a cool effect, and can be easily washed with water [5]. The hydrogel is expected to have a consistency as an ointment because it is easy to apply to the skin topically. The making of this chitosan gel used carbopol as a gelling agent and propylene glycol as humectant. Carbopol is often used as gelling agent because it can give good gel characteristics. Carbopol gel also has good stability against heat [6]. The recommended use of carbopol is at a concentration of $0.50-2.00 \%$. As for the use of Propylene glycol as humectant, it is because it has good solubility with water and also a good solvent for methylparaben preservatives. Propylene glycol is also best used on damaged skin. Other materials used were methylparaben as a preservative, Triethanolamine (TEA) as the basic agent and neutralizing agent that helps to characterize gel [7] and distilled water. Chitosan in the form of free amino is not always soluble in water at $\mathrm{pH}$ over 6.5 so that it requires acid to dissolve it. Chitosan is soluble in acetic acid and dilute formic acid. Therefore, this research used 1\% acetic acid solution as much as $10 \mathrm{ml}$ to dissolve 1 gram of chitosan into a viscous period that can be mixed with other materials.

\subsection{The Results of Physical Stability Test of Chitosan Gel}

Organoleptic observation results, including color, odor, and homogeneity during storage at room temperature $25^{\circ} \mathrm{C}$ and high temperature of $40^{\circ} \mathrm{C}$ in each gel formula, show different results. In general, the results of organoleptic test show that the three formulas are homogeneously stable during 56-day storage. However, in terms of color and odor changes, the higher the concentration of carbopol, the faster the color and odor changes.

\subsection{The Results of pH Stability Test of Chitosan $\mathrm{Gel}$}

The $\mathrm{pH}$ test examines the $\mathrm{pH}$ value of each formula made. The test was performed by using $\mathrm{pH}$ meter. The $\mathrm{pH}$ of the chitosan gel should be 
adjusted to the $\mathrm{pH}$ of the skin, namely, between 4.5-6.5 in order not to cause irritation and to improve the acceptability of consumers. Based on $\mathrm{pH}$ measurement data during storage at $25^{\circ} \mathrm{C}$ and $40^{\circ} \mathrm{C}$, it can be concluded that the $\mathrm{pH}$ of the three formulas are stable (Figure 1 and 2).

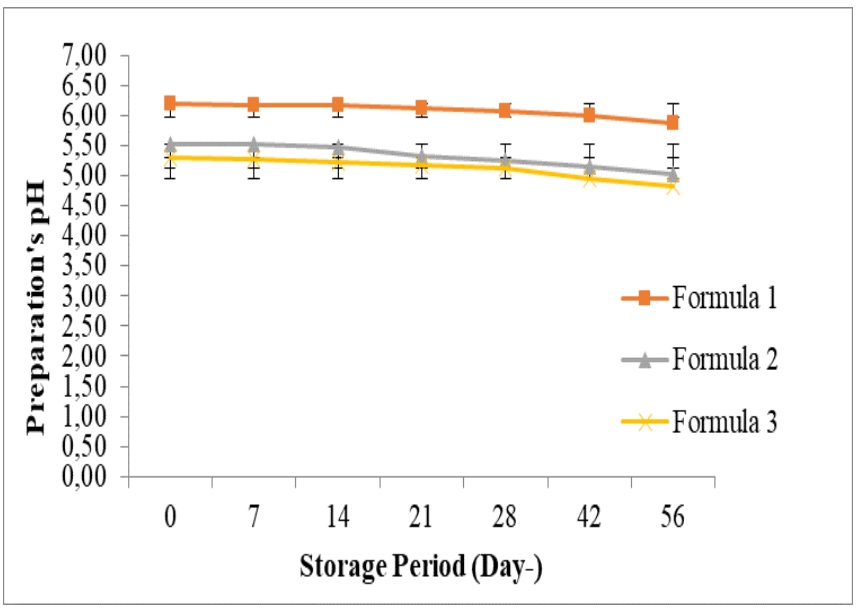

Figure 1. The Graphics of PH Change during Storage Period at $25^{\circ} \mathrm{C}$

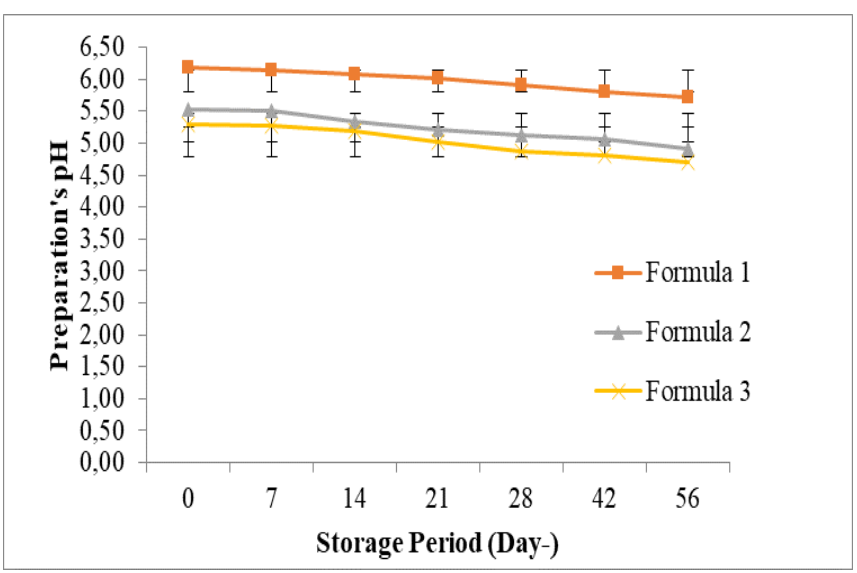

Figure 2. The Graphics of PH Change during Storage Period at $40^{\circ} \mathrm{C}$

\subsection{The results of Viscosity test of Chitosan Gel}

Viscosity is a resistance statement of a liquid to flow. The higher the viscosity, the higher the resistance [8]. The desired viscosity in the criterion is between 10-40 Pa.s because these gels are expected to have an ointment-like viscosity in order to have a longer skin contact time than the usual gel. The viscosity level also aims to minimize the water content of the gel so that when applied to the injured skin, it can reduce microbial growth. High water content is also feared to make the process of blood clots slower because the skin may become more moist. The smaller viscosity shift means the better the gel's physical stability. A gel is said to be stable if there is no change in its flow properties. Accordingly, it can be concluded that of the three gel formulas, formula 1 has the best stability among all tested formulas, indicated by the lowest value of viscosity shift i.e. $9 \%$ at $25^{\circ} \mathrm{C}$ and $13.8 \%$ at $40^{\circ} \mathrm{C}$ (Figure 3 and 4).

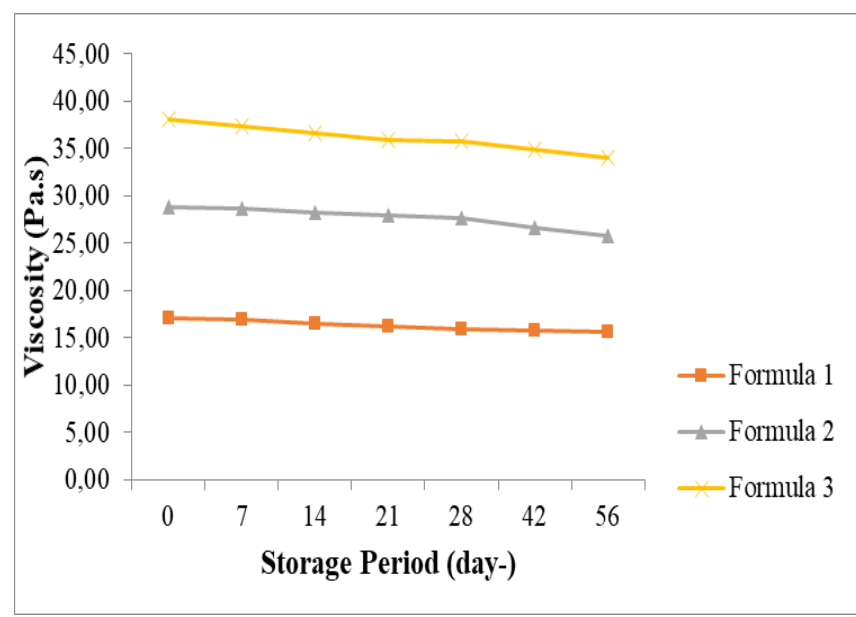

Figure 3. The Graphics of Viscosity Change during Storage Period at $25^{\circ} \mathrm{C}$

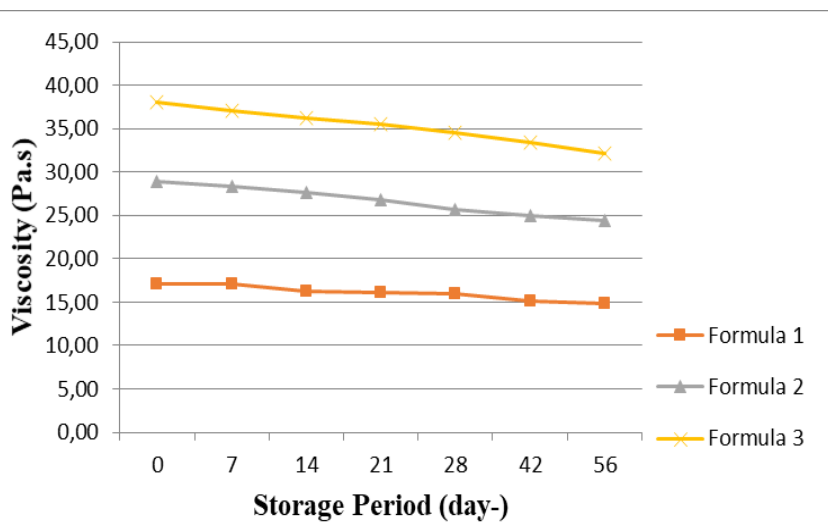

Figure 4. The Graphics of Viscosity Change during Storage Period at $40^{\circ} \mathrm{C}$

\subsection{The results of Diverse Power test of Chitosan $\mathrm{Gel}$}

According to Garg et.al (2002), diverse power test is used for determining the easiness of the application of a semisolid preparation on the skin. Diverse power is inversely proportional to the viscosity, namely the higher the viscosity the lower the generated power, vice versa, the lower the viscosity the higher the generated power [9]. This theory is also reinforced by the results of carbopol 
optimization that has been done before. The desired gel permeability in the criteria is $4-7 \mathrm{~cm}$. Moreover, the measurements of gel's diverse power during storage at $25^{\circ} \mathrm{C}$ and $40^{\circ} \mathrm{C}$ indicate that there is a change in terms of diverse power (Figure 5 and 6). This change also occurs because of viscosity shift that has been seen before.

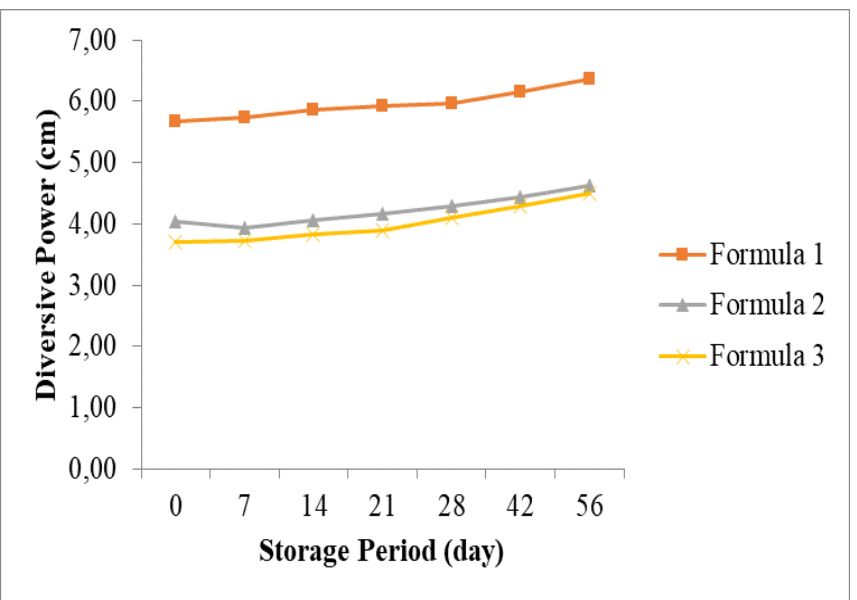

Figure 5. The Graphics of Divertive Power Change during Storage Period at $25^{\circ} \mathrm{C}$

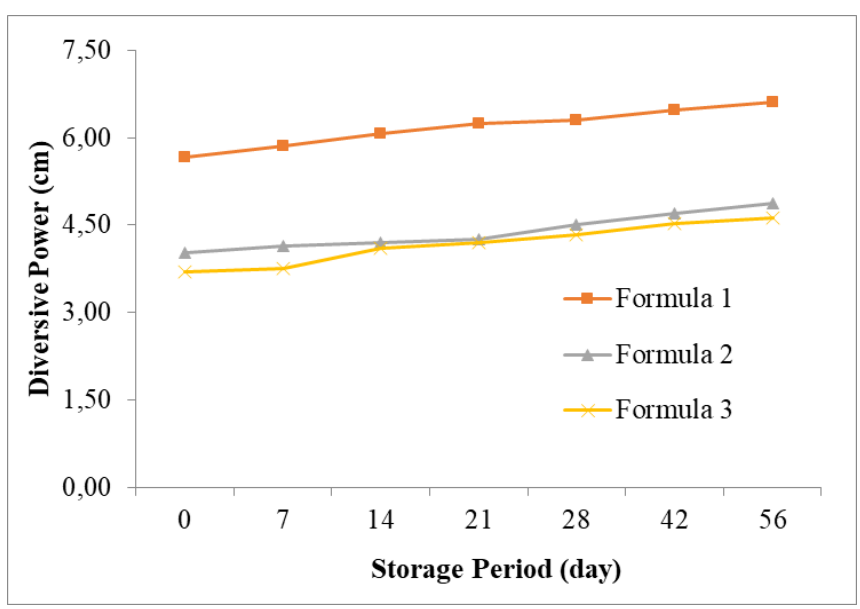

Figure 6. The Graphics of Diverse Power Change during Storage Period at $40^{\circ} \mathrm{C}$

\subsection{The observation results of Cycling Test}

This test was done to observe the synthesis of gel. Syneresis was calculated by measuring the weight loss during storage then compared it with the initial weight of the gel. This test was conducted for 6 cycles or 12 days and examined whether there is any change in each Chitosan Gel.

Syneresis is the release of water from the gel when the gel contracts so that it tends to squeeze the water out of the cell. The observation results of Cycling Test show the percentage value of the weight reduction due to 6-cycle storage. The weight reduction of formula 1 is $3,2 \%$, formula 2 is $2,3 \%$, and formula 3 is $1.9 \%$. As for overcoming the decrease in water holding and syneresis, it can be added by more carbopoles or other stabilizers in the form of hydrocolloids or water-soluble polymers.

Table 2. The Observation Results of Cycling Test of Chitosan Gel

\begin{tabular}{cccc}
\hline Day- & F1 & F2 & F3 \\
\hline 0 & 0 & 0 & 0 \\
56 & 96,8 & 97,7 & 98,1 \\
Loose weight $(\mathrm{g})$ & 3,2 & 2,2 & 1,9 \\
$\%$ & $2,8 \%$ & $2,3 \%$ & $1,9 \%$ \\
\hline
\end{tabular}

\subsection{The observation results of Hedonic Test}

Hedonic test were conducted on 20 respondents using texture, aroma, and appearance parameters with Formula 1 as one showing the highest average values, namely, 4 for texture, 3 for aroma, and 3.5 for appearance. The results of statistical analysis using Kruskal-Wallis analysis method obtains value of significance i.e. p-value $<$ critical limit 0,05 for texture, aroma, and appearance parameters, which means it receives $\mathrm{H} 1$, namely the variation of the treatments make significant impacts on respondents' hedonic value. Therefore, it is concluded that the difference of carbopol 940 concentrations in chitosan gel influences the hedonic value of 20 respondents.

\section{Conclusion}

Based on this research results obtained from the results of physical stability test and hedonic test, the best formulation of chitosan gel from vanammei shrimp shells (Litopenaeus vanamei) with a gelling agent carbopol 940 is formula 1 . Formula 1 is composed of chitosan $1 \%, 10 \mathrm{ml}$ Acetic Acid- 1\%, carbopol 940 0,5\%, propylene glycol $10 \mathrm{ml}$, methylparaben $0.1 \%$, Propylparaben $0.01 \%$, Triethanolamine $0.25 \%$, and distilled water ad $100 \mathrm{ml}$.

The results of physical stability test of chitosan gel during 56-day storage show that formula 1 has the best result of all parameters. Formula 1 has 5.8-6.2 $\mathrm{pH}$ at $25^{\circ} \mathrm{C}$ and $40^{\circ} \mathrm{C}$, the best organoleptic stability, $9 \%$ viscosity shift at $25^{\circ} \mathrm{C}$ and $13.8 \%$ at $40 \mathrm{oC}, 10.9 \%$ shift of dispersive power at $25^{\circ} \mathrm{C}$ 
and $14.4 \%$ at $40^{\circ} \mathrm{C}$, and values in the hedonic test namely 4 for texture, 3 for aroma, and 3.5 for appearance.

\section{Suggestion}

Further research may be done to determine the chemical stability of these chitosan gel and the effectiveness of its activity as blood clotting of the wound as well.

\section{References}

[1] Syamsuhidayat, Wim de Jong,. Buku Ajar Ilmu Bedah . Edisi 2. Buku Kedokteran. Jakarta. EGC; 2004.

[2] Aranaz,I., Mengibar, M., Harris, R., Panos, I., B. Miralles, Acocta N., Galed, G.\& Heras.A. Functional Characterization of Chitin and Chitosan. Current Chemical Biology, 2009; 3 : 203-230.

[3] Jung BO, Na J, Kim HC. 2007. Synthesis of chitosan derivates with anionic groups and its biocompatible in vitro. J. Ind. Eng. Chem.
Vol.13. No. 5. p.772776.

[4] Yogeshkumar N, Gavhane., Shinde Vikram R.,Bhagat Abhimanyu., and Yadav Adhikrao V. International Journal Of Pharmacy And Pharmaceutical Sciences. Stability Of AloeGel By Formulating Polyelectrolyte Complex Beads, 2010; Vol 2, Suppl 2.

[5] Voigt, R. Buku Pelajaran Teknologi Farmasi. Edisi ke-5. Yogyakarta. Gadjah Mada University Press; 1994.

[6] Osborne, D.W. \& A.H. Amann. Topical Drug Delivery Formulations. Marcel Dekker Inc., USA. 1990; 47-66.

[7] Rowe, R.C., Sheskey, P.J. and Quinn M., E. Handbook of Pharmaceutical Excipients. LexiComp: American Pharmaceutical Association, Inc. 2009

[8] Sinko, P. J. Martin Farmasi Fisika dan Ilmu Farmasetika edisi 5. Jakarta. Buku Kedokteran EGC; 2011.

[9] Garg A, Aggarwal D, Garg S, Sigla AK. Spreading of semisolid formulation: an update. Pharmaceutical Tecnology. 2002; 9(2):84-102 